\title{
Classical conditioning of jaw movements in the pigeon: Acquisition and response topography
}

\author{
MONIKA REMY and H. PHILIP ZEIGLER \\ Hunter College, New York, New York
}

\begin{abstract}
Previous studies have shown (1) that the form of the pigeon's conditioned keypecking response resembles that of its ingestive pecking response, (2) that both ingestive and conditioned pecking in the pigeon are compound responses, including both transport (neck-movement) and gape (jawmovement) components, and (3) that during operant conditioning or autoshaping of pecking behavior, the gape component comes under the associative control of the CS. In the present study, the gape component was experimentally isolated and a classical conditioning paradigm (water US) was used to bring jaw movements under the control of a CS (light). The results indicate that the topography of the jaw-movement $\mathrm{CR}$ is very similar to, though more variable than, that of the UR. They are consistent with the hypothesis that reported similarities in the form of ingestive and conditioned pecking responses reflect, in part, classical conditioning of the gape component.
\end{abstract}

Whether acquired under an operant or a respondent paradigm, the form of the pigeon's conditioned keypecking response (the conditioned response [CR]) resembles that of the ingestive response (the unconditioned response [UR]) to the reinforcer (Jenkins \& Moore, 1973; Wolin, 1968). This observation has stimulated a substantial body of empirical and theoretical work on the associative origins of such similarity (see, e.g., Locurto, Terrace, \& Gibbon, 1981; Woodruff \& Williams, 1976). In all these studies, the pigeon's pecking behavior has been treated as a unitary response, elicited initially by the reinforcer (the unconditioned stimulus [US]) and coming under the associative control of the conditioned stimulus (CS) as an integral unit (e.g., Lucas, Vodraska, \& Wasserman, 1979; Woodruff, Morrison, \& Williams, 1974).

However, the analysis of eating behavior in the pigeon (Zeigler, Levitt, \& Levine, 1980) has demonstrated that pecking is composed of separable transport (headmovement) and gape (jaw-movement) components, functionally related, respectively, to localization and grasping behaviors. The two components are differently affected by the same neural manipulations. Thus, reversible "visual decerebration" (i.e., removal of forebrain visual inputs) profoundly disrupts peck localization without affecting the precision of the jaw-movement component in

This research was supported by grants from the NSF (BNS-88-10722) and NIMH (MH-08366), by Research Scientist Award MH-00320, and by the Biopsychology Program, Hunter College (CUNY). Partial support for M.R. was provided by a Fellowship from the Deutsche Forschungsgemeinschaft. We appreciate the advice of Peter Balsam (Barnard College) at various stages of the study and the assistance of Bertram Ploog in the revision of the manuscript. M. Remy is currently at Fakultät Biologie, Ruhr University, Bochum, Germany. Correspondence should be addressed to H. P. Zeigler, Department of Psychology, Hunter College, 695 Park Ave., New York, NY 10021. grasping (Jäger, Arends, Schall, \& Zeigler, 1992). Similarly, following trigeminal deafferentation, an experimental treatment that disrupts both peck localization and grasping, the time course of recovery differs for the two components (Bermejo \& Zeigler, 1989).

The dissociability of the transport and gape components has also been demonstrated for conditioned keypecking behavior. Concurrent monitoring of the gape and transport components during autoshaping shows that although both come under the associative control of the conditioning stimulus, the time course of acquisition differs for the two components (Allan \& Zeigler, in press). Moreover, the two components have been brought under operant control in the same conditioning experiment using a different reinforcement schedule for each component (Deich, Allan, \& Zeigler, 1988). Finally, operant conditioning of the pigeon's jaw movements has been demonstrated under conditions in which the transport component is eliminated by head fixation (Mallin \& Delius, 1983). Such observations suggest that although the transport and gape components of pecking are functionally related and are temporally linked by the presence of the US or CS, they may be under the control of different causal mechanisms.

Although similarities in the topography of the UR and CR have been observed for both components (e.g., Jenkins \& Moore, 1973), such similarities are more clearly evident for the gape than for the transport component. Jaw movements during both eating and foodreinforced keypecking are episodic and vary in their peak gape amplitude with the size of the food pellet. Jaw movements during drinking and water-reinforced pecking are rhythmic, with small and relatively invariant peak gape amplitudes (LaMon \& Zeigler, 1984, 1988).

Taken together, these lines of evidence suggest that the reported similarities in the form of conditioned and un- 
conditioned pecking may reflect, in part, the independent classical conditioning of the gape component. The present study is designed to test this hypothesis by comparing the topography of the UR and CR during classical conditioning of the jaw-movement response under circumstances in which the occurrence of the transport component is eliminated by head fixation.

The conditioning paradigm used is similar to those of our previous autoshaping studies. However, the use of food reinforcers is not feasible in the "head-fixed" pigeon, because eating in this species involves head as well as jaw movements (Zeigler et al., 1980). In the present study, a water US was used and the topography of the UR and CR were monitored during the acquisition of a conditioned jaw-movement response.

\section{METHOD}

\section{Subjects}

Six experimentally naive White Carneau pigeons were housed in individual cages under free-feeding conditions. Prior to training, the subjects were anesthetized with Equithesin $(0.2 \mathrm{ml} / 100 \mathrm{~g}$ body weight), and a small metal headblock with a tapped hole was fixed to the skull with dental cement. Conditioning and extinction sessions were carried out under water deprivation and conducted on alternate days. That is, each session was preceded by a 48-h period of water deprivation and followed by a $40-\mathrm{min}$ period of ad lib drinking.

\section{Apparatus}

Testing was carried out in a sound-attenuated chamber illuminated with a white (25-W) houselight. The apparatus used for head fixation and water delivery has been described in detail elsewhere (Mallin \& Delius, 1983; Remy \& Emmerton, 1991, Figure 1), as has the system for monitoring jaw movements (Deich, Houben, Allan, \& Zeigler, 1985). Briefly, each pigeon was restrained in a cloth bag, and using the headblock, its head was fixed in position just above the opening of a small plexiglass container. The US was a drop of about $0.2 \mathrm{ml}$ of water, delivered into the container from a solenoid-activated reservoir. Water delivery submerged the beak tip and elicited drinking in the water-deprived pigeon without specific training.

Jaw-movement responses were monitored using a magnetosensitive (Hall-effect) transistor (Sprague 2UGN3503U930) glued to the upper beak and a samarium-cobalt magnet glued to the lower beak with cyanoacrylate cement. The transistor generated a voltage proportional to the strength of the magnetic field, which was directly related to variations in the interbeak distance (gape), and this voltage was amplified and digitized through an $A / D$ interface (sampling rate $4 \mathrm{msec}$ ). The transducing system was calibrated at the start and end of each session by inserting a series of rods (diameters 1-12 $\mathrm{mm}$ ) between the beaks and recording the digital readings produced by different interbeak distances.

\section{Behavioral Testing Procedures}

Testing was carried out on alternate days, and each subject was exposed to 13 sessions, divided as follows: adaptation (3), conditioning (8), and extinction (2).

Adaptation. Adaptation to the chamber and jaw-movement transducer was carried out in two 20-min sessions, during which jaw movements were recorded in undeprived, restrained, but not headfixed, subjects. Following a 48-h water-deprivation period, adaptation to head fixation was accomplished in a single 20-min session, during which drinking responses to water delivery were recorded. Assignment to control and experimental groups $(n=3)$ was based upon the subject's drinking behavior in the last adaptation session, in order to produce approximately equal frequencies of drinking responses in the two groups.

Conditioning. For the experimental subjects, each session consisted of $\mathbf{4 0}$ trials, and the conditioning paradigm included three components: (1) A 60-sec variable-time (VT) intertrial interval (ITI), (2) a 6-sec CS period, and (3) a 6-sec US period. For control subjects, each trial was also divided into three segments, equivalent in duration $(6 \mathrm{sec})$ to the pre-CS, CS, and US periods in the experimental group. However, for the control subjects, US presentation was "random," that is, timed by an independent VT 60-sec schedule and not correlated with CS presentation. Because there were no constraints on the timing of US presentation, instances of US-CS contiguity could occur, but most US presentations occurred during the ITI. The total number of CS and US presentations was identical for both groups. Jaw movements were recorded during the last $6 \mathrm{sec}$ of the ITI, which served as a pre-CS period, and during the CS and US presentations.

Extinction. During the extinction sessions, presentation of the US was canceled.

\section{RESULTS}

The analog data generated by the magnetosensitive transducer were converted by the $A / D$ device and stored as a string of digital values by a computer program that subsequently transformed the data into millimeter values for analysis. Individual jaw-movement responses were defined and peak gape values calculated using an algorithm that sampled the converted data and determined the highest value that occurred after a minimum of five increasing values (peak gape), as well as the interval between successive pairs of peak gapes (interresponse times [IRTs]). Response frequencies and durations were calculated directly from the visual display. Figure 1 presents a record of jaw movements during a single conditioning trial taken from the last acquisition session of an experimental subject.

\section{Response Acquisition}

Figure 2A indicates, for each subject, the frequency of jaw-movement responses during the CS interval over the eight sessions as a percentage of the total number of responses emitted in the combined CS and pre-CS intervals. All experimental subjects showed similar trends, with performance above $80 \%$ in the final session and a marked reduction of responses during extinction. Two of the controls showed a decline in responses across sessions, but none showed any marked changes during extinction. An analysis of variance (ANOVA) indicates that the two groups differed significantly from each other $[F(1,4)=$ $40.72, p<.05]$. A separately performed linear trend ANOVA indicated that the group means for the two groups were increasing and decreasing, respectively. Results for the experimental and control groups were $[F(1,14)=7.67$ and $F(1,14)=7.21$, respectively; both were significant at $p<.05$ ].

Figure 2B plots the cumulative frequencies of jawmovement responses in the pre-CS and CS intervals for both groups. In the experimental group, pre-CS and CS frequencies were initially comparable, but over successive sessions CS rates increased markedly while pre-CS 
(A)

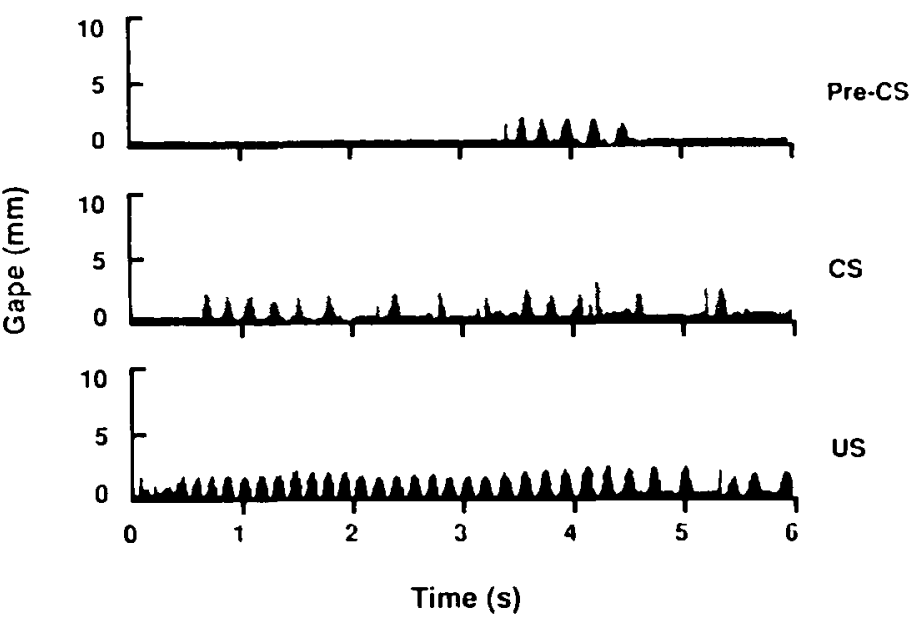

(B)
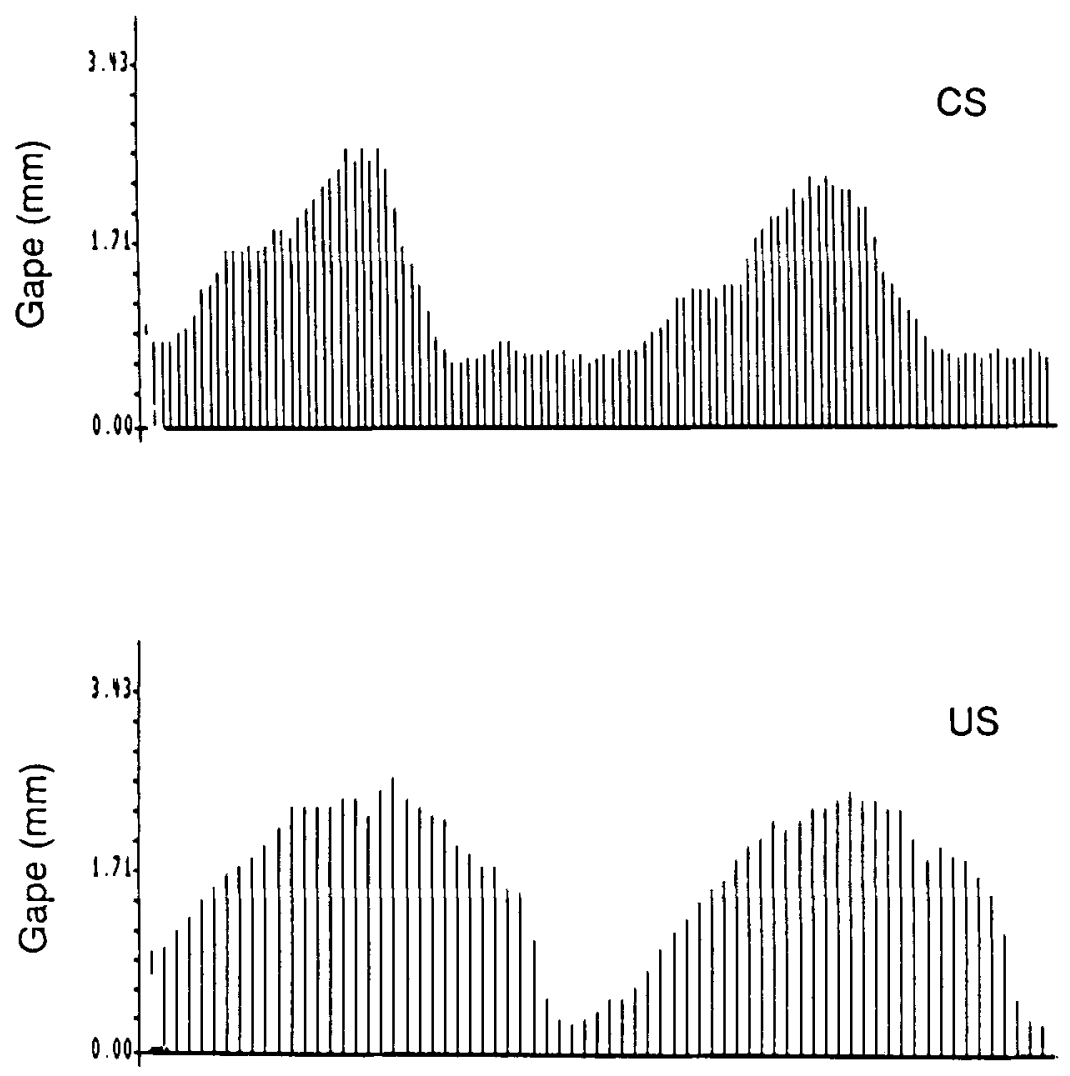

Figure 1. (A) Jaw movements (variations in gape) recorded during a single acquisition trial in an experimental subject. Data are shown for each of the 6-sec intervals (pre-CS, CS, US). (B) Details of the "gape record" to illustrate similarities and differences between conditioned and unconditioned jaw movements.

rates asymptoted at low levels. For the control group, response rates for both intervals asymptoted at the same low rate. Differences between the two groups were maintained over the two extinction sessions (cumulative frequencies: control, $M=68, S D=17.2$; experimental, $M=263$, $S D=94.7)$.

\section{Response Topography}

As the record presented in Figure 1 indicates, the CS and US intervals were characterized by the cyclic repetition of jaw opening and closing movements of low amplitude $(<3 \mathrm{~mm})$ and roughly similar durations. Responses during the $\mathrm{CS}$ interval were more likely to be interrupted 
(A)

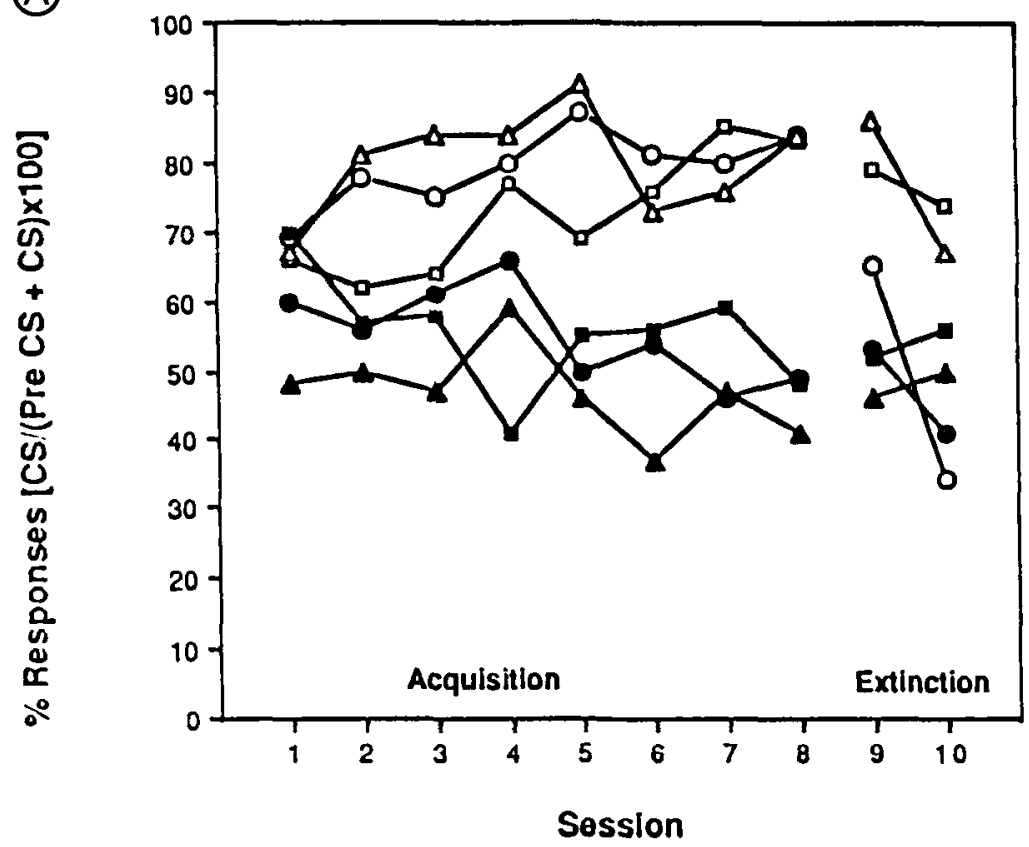

(B)

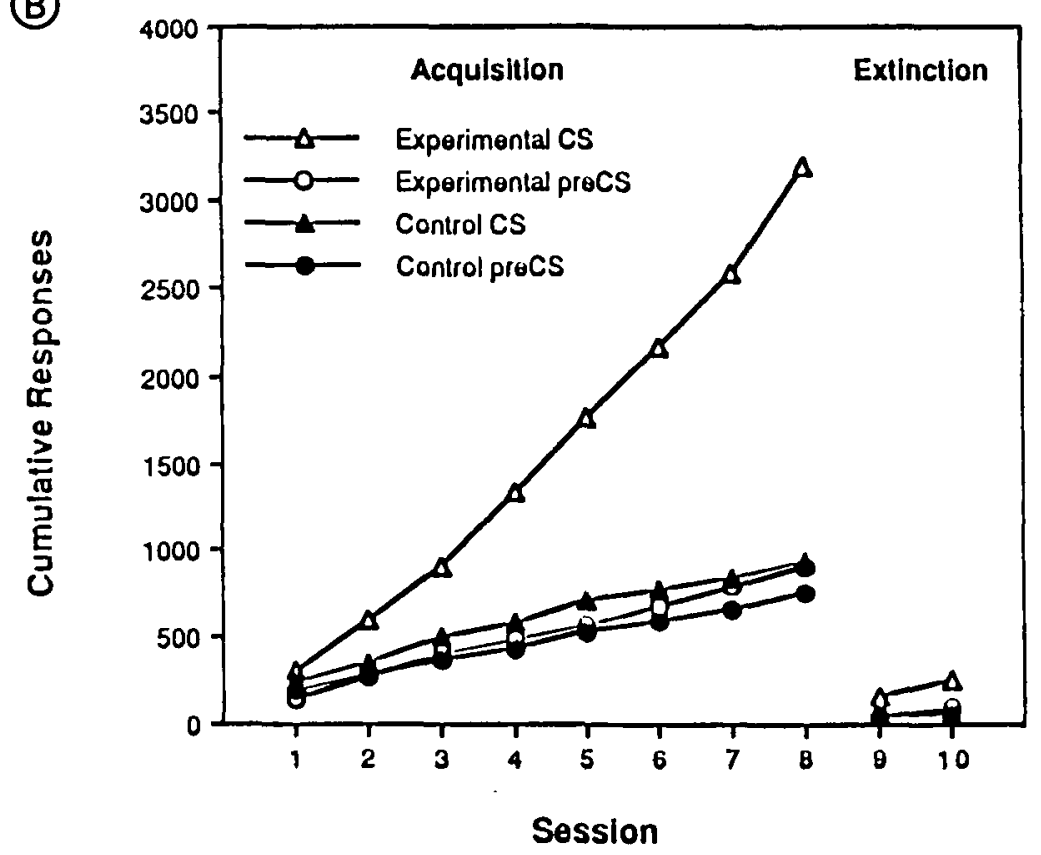

Figure 2. Acquisition of the classically conditioned jaw-movement ("gape") responses in pigeons. (A) Frequency of responding in the CS intervals as a percentage of total (CS + pre-CS) responses for individual subjects. (B) Mean cumulative frequencies of jaw movements during the pre-CS and CS intervals over the course of acquisition. (Open symbols = experimental subjects; closed symbols = control subjects; Trials 1-8 $=$ acquisition trials; Trials 9 and $10=$ extinction trials. 
Table 1

Topography of Conditioned and Unconditioned Responses During the Final Acquisition Session

\begin{tabular}{lcccccc} 
& & \multicolumn{2}{c}{ Peak Gape* } & & \multicolumn{2}{c}{ Duration $\dagger$} \\
\cline { 3 - 4 } \cline { 6 - 7 } Subject & Response & $M$ & $S D$ & & $M$ & $S D$ \\
\hline 8929 & UR & 2.17 & 0.35 & & 149 & 20.1 \\
& CR & 1.59 & 0.67 & & 143 & 39.4 \\
8937 & UR & 1.85 & 0.25 & & 162 & 22.3 \\
& CR & 2.04 & 0.37 & & 174 & 41.9 \\
9007 & UR & 2.59 & 0.37 & & 152 & 12.3 \\
& CR & 3.31 & 1.60 & & 186 & 32.6 \\
\hline
\end{tabular}

*In millimeters. †In milliseconds.

by periods of nonresponding of relatively variable duration, and CR frequency was lower than that in the US intervals.

These observations were confirmed by quantitative analysis. Table 1 compares the peak gape amplitudes and durations of a sample of UR and CR individual jawmovement responses recorded during the middle 10 trials of the last acquisition session in experimental subjects. There was considerable overlap in the UR and CR distributions, and group differences in response amplitude and duration were not significant. However, for both measures, the variability of the CR distributions was consistently greater than for the UR distributions. Figure 3 presents frequency distributions of IRTs for the CRs and URs. The IRTs for the URs were narrowly distributed, with more than $90 \%$ of the responses lying between 200 and 300 msec. The distribution of IRTs for the CRs was considerably broader, containing a substantial number of intervals shorter or longer than the mean IRT for the URs.

\section{DISCUSSION}

Previous studies of classical conditioning in the pigeon include aversive conditioning of autonomic responses (e.g., Cohen \& Durkovic, 1966; Cohen \& MacDonald, 1971) and autoshaping of the pigeon's keypecking response to intraoral reinforcement (Lucas et al., 1979; Woodruff et al., 1974). The present study demonstrates classical conditioning of jaw opening and closing movements in the pigeon, and these movements have also been a target response in classical conditioning experiments with the rabbit (Smith, DiLollo, \& Gormezano, 1966).

Our results indicate that jaw movements elicited as a UR by a water US may be brought under the control of a visual CS using a classical conditioning paradigm. The associative nature of that control may be inferred from the differences in the performance of the control and experimental subjects during both the acquisition and extinction phases of the experiment. The subjects in both groups emitted substantial numbers of responses in the first session, suggesting the presence of an alpha response, but the frequency of responding in the two groups differed significantly in subsequent sessions, increasing in the experimental group and decreasing in the control group. Differences were particularly striking in the cu- mulative curves shown in Figure $2 \mathrm{~B}$, and such differences were also characteristic of the (autoshaped) conditioned keypecking of unconstrained pigeons (Allan \& Zeigler, in press).

During the extinction phase, responding was markedly reduced in the experimental subjects, whereas the control subjects showed neither marked increases nor decreases in responding. This observation suggests that the responses of the experimental subjects are under the associative control of the CS. The failure to find either marked increases or decreases in responding during simple extinction following noncontingent CS-US presentations suggests the absence of such control by the CS and is consistent with the report of Lindblom and Jenkins (1981).

Drinking in pigeons involves both a transport and a gape component. The latter is characterized by cyclic opening and closing, movements of the jaws, emitted at frequen-
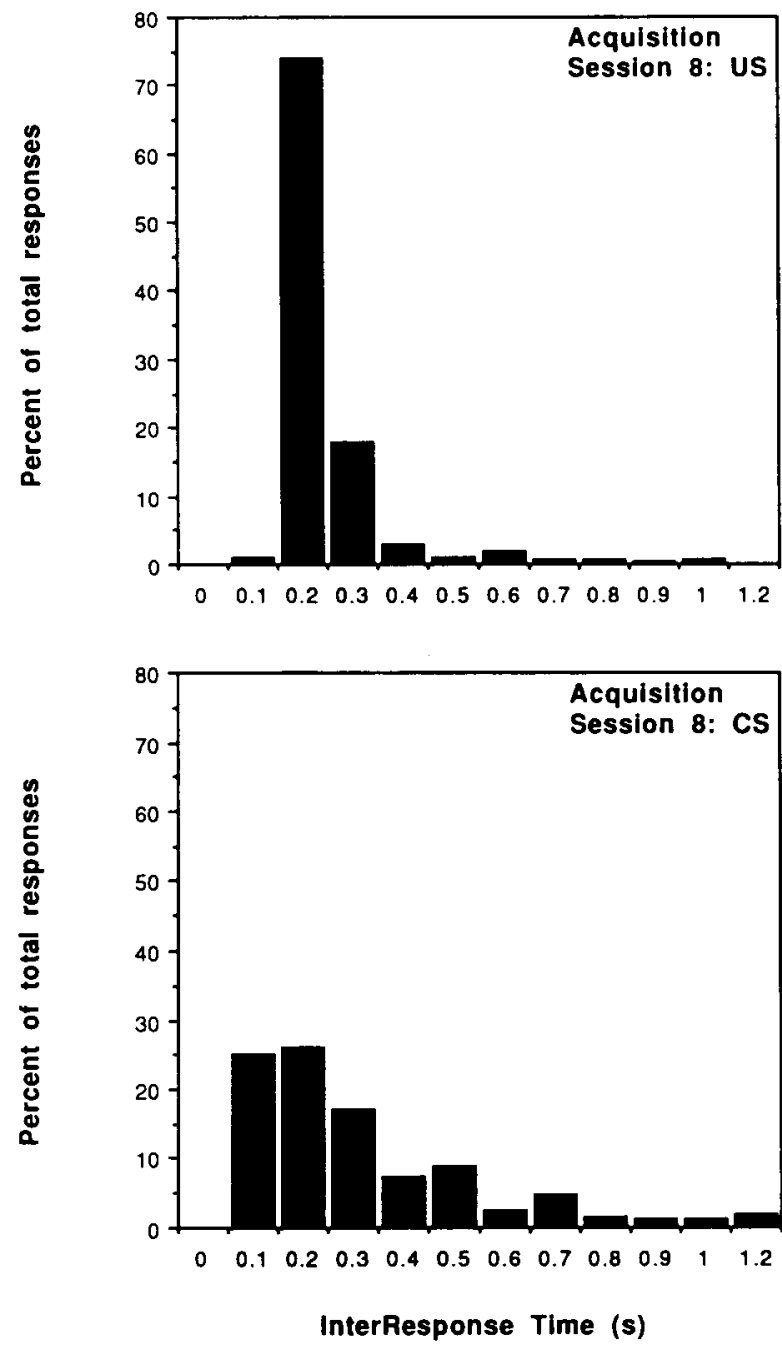

Figure 3. Frequency distributions of US and CS interrespons times for a set of conditioning trials recorded during the final acqui sition session in the experimental subjects. 
cies of between 5 and 7 cycles per second, with peak amplitudes of 1.5-3.5 mm and durations of $100-300 \mathrm{msec}$ (Klein, LaMon, \& Zeigler, 1983). Similar values were found for the URs in the head-fixed pigeon. Conditioned response topography in the present experiment was measured in the absence of interaction with a manipulandum (pecking response key), but our results are similar to those seen during conditioned keypecking in the unconstrained pigeon (Allan \& Zeigler, in press). In both preparations, the distributions of CR amplitudes, durations, and IRTs overlapped with those of the UR, but tended to cover a broader range. Variability in CR topography may reflect a diminished degree of stimulus control exerted over the target effector system by the visual CS, in contrast to the continuous orosensory stimulation provided to the jaw motor system by the US of water in the oral cavity.

The present findings may clarify associative mechanisms underlying the form of the pigeon's conditioned keypecking response. In the unconstrained conditioning situation, both transport and gape components come under the associative control of the CS so that both are likely to contribute to the form of the CR. Experimental isolation of the gape component permits us to parcel out its contribution. Our results are consistent with the hypothesis that independent classical conditioning of the gape component may be an important source of conditioned response topography in autoshaping of the pigeon's keypecking response.

It has now been shown that the gape component of the pigeon's pecking response may be experimentally isolated and brought under associative control, utilizing either operant or classical conditioning paradigms and in the presence or absence of the transport component. These observations suggest that gape is causally, though not functionally, independent of transport. Yet, the ingestive pecking response normally occurs as an integral unit, and when the US is applied intraorally during autoshaping, the conditioned pecking response includes both components, even though transport is not a UR to this US (Gormezano \& Kehoe, 1975).

The origins of this temporal linkage may, perhaps, be found in the development of the pigeon's pecking response. Several investigators (Deich \& Balsam, in press; van Gennip, 1988) have shown that the jaw-movement component occurs earlier in ontogeny, that at a later stage it may occur in the absence of transport, and that the two response components have different time courses during development. Taken with the neurobehavioral evidence (Bermejo \& Zeigler, 1989; Jäger et al., 1992), these observations suggest that the linkage between the transport and gape components is not inherent in the neural organization of pecking behavior, but reflects the operation of parallel processes that may have become temporally linked during development by stimulus and reinforcer contingencies. Similar conclusions have been reached with respect to the temporal organization of reaching and grasping behavior in humans (von Hofsten, 1990).

\section{REFERENCES}

Allan, R. W., \& Zeigler, H. P. (in press). Conditioning of the pigeon's jaw movement (gape) responses during autoshaping of the keypecking response. Journal of the Experimental Analysis of Behavior.

Bermejo, R., \& ZeIgleR, H. P. (1989). Trigeminal deafferentation and prehension in the pigeon. Behavioral Brain Research, 35, 55-61.

CoHEN, D. H., \& DuRkovic, R. G. (1966). Cardiac and respiratory conditioning, learning, differentiation and extinction in the pigeon. Journal of the Experimental Analysis of Behavior, 9, 681-688.

Cohen, D. H., \& MacDonald, R. L. (1971). Some variables affecting orienting and conditioned heart rate responses in pigeon. Journal of Comparative \& Physiological Psychology, 74, 123-133.

Deich, J. D., Allan, R. W., \& Zeigler, H. P. (1988). Conjunctive differentiation of gape during food-reinforced keypecking in the pigeon. Animal Learning \& Behavior, 16, 268-276.

Deich, J. D., \& BALSAM, P. (in press). The form of early pecking in the ring dove squab (Streptopelia roseogrisea). Journal of Comparative Psychology.

Deich, J. D., Houben, D., Allan, R. W., Zeigler, H. P. (1985). "On-line" monitoring of jaw movements in the pigeon. Physiology \& Behavior, 35, 307-311.

Gormezano, 1., \& Kehoe, E. J. (1975). Classical conditioning: Some methodological-conceptual issues. In W. K. Estes (Ed.), Handbook of learning and cognitive processes: Vol. 2. Conditioning and behavioral theory (pp. 143-179). Hillsdale, NJ: Erlbaum.

Jäger, R., ARends, J. J. A., Schall, U., Ze Zelgler, H. P. (1992). The visual forebrain and eating in the pigeon. Brain, Behavior \& Evolution, 39, 153-168.

Jenkins, H. M., Moore, B. R. (1973). The form of the autoshaped response with food or water reinforcers. Journal of the Experimental Analysis of Behavior, 20, 163-181.

KleiN, B. G., LAMon, B., \& Zeigler, H. P. (1983). Drinking in the pigeon: Response topography and spatiotemporal organization. Joumal of Comparative Psychology, 97, 178-181.

LAMoN, B. C., \& Zeigler, H. P. (1984). Grasping in the pigeon (Columba livia): Stimulus control during conditioned and consummatory responses. Animal Learning \& Behavior, 12, 223-231.

LAMon, B., \& ZEIGLER, H. P. (1988). Control of pecking response form in the pigeon: Topography of ingestive behaviors and conditioned keypecks with food and water reinforcers. Animal Learning \& Behavior, 16, 256-267.

LindBLOM, L. L., \& JENKINS, H. M. (1981). Responses eliminated by noncontingent or negatively contingent reinforcement recover in extinction. Journal of Experimental Psychology: Animal Behavior Processes, 7, 175-190.

Locurto, C. M., Terrace, H. S., \& Gibbon, J. (1981). Autoshaping and conditioning theory. New York: Academic Press.

Lucas, G. A., Vodraska, A., \&asserman, E. A. (1979). A direct fluid delivery system for the pigeon. Joumal of the Experimental Analysis of Behavior, 31, 285-288.

Mallin, H. D., \& Delius, J. D. (1983). Inter- and intraocular transfer of color discrimination with mandibulation as an operant in the fixed-head pigeon. Behavior Analysis Letters, 3, 297-309.

Remy, M., \& Emmerton, J. (1991). Directional dependence of intraocular transfer of stimulus detection in pigeons (Columba livia). Behavioral Neuroscience, 105, 647-652.

Smith, M. C., Dilollo, V., Gormezano, I. (1966). Conditioned jaw movement in the rabbit. Journal of Comparative \& Physiological Psychology, 62, 479-483.

VAN GENNIP, E. M. S. (1988). A functional morphological study of the feeding system in pigeons (Columba livia L.): Behavioral flexibility 
and morphological plasticity. Unpublished doctoral dissertation, University of Leiden, Leiden, The Netherlands.

von Hofsten, C. (1990). A perception-action perspective on the development of manual movements. In $\mathrm{M}$. Jeannerod (Ed.), Attention and performance (Vol. 13, pp. 739-762). Hillsdale, NJ: Erlbaum.

Wolin, B. R. (1968). Differences in the manner of pecking a key in pigeons reinforced with food and water. In A. C. Catania (Ed.), Contemporary research in operant behavior (p. 286). Glenview, IL: Scott-Foresman.

WoOdruff, G., Morrison, R. R., * Williams, D. R. (1974, November). Consummatory fixed action pattems underlying conditioned keypecking. Paper presented at the meeting of the Psychonomic Society, Boston.
Woodruff, G., WiLliams, D. R. (1976). The associative relationship underlying autoshaping in the pigeon. Joumal of the Experimental Analysis of Behavior, 26, 1-13.

Zeigler, H. P., Levitt, P., \& Levine, R. R. (1980). Eating in the pigeon (Columba livia): Response topography, stereotypy and stimulus control. Joumal of Comparative \& Physiological Psychology, 94, 783-794.

(Manuscript received May 26, 1991; revision accepted for publication July 28,1992 .) 